\title{
Chemistry and Pharmaceutical Sciences always together
}

"The International Year of Chemistry will give a global boost to chemical science in which our life and our future are grounded," says Jung-Il Jin, president of the International Union of Pure \& Applied Chemistry (IUPAC) and a professor of chemistry at Korea University, in Seoul, South Korea. "This designation by the United Nations is truly exciting," ACS President Thomas H. Lane says. "It is an opportunity for our world to learn more about the transforming powers of chemistry."

The celebration of the International Year of Chemistry will be held next year, 2011, involving many and important events for the recognition of the powers of chemistry in the past, present and in the future of mankind.

Brazil is completely involved in the celebration and its scientists are totally committed to make the next year a landmark and a great repercussion in the current life will then be expected through the contribution of the Brazilian Chemistry.

In this context, we must not forget, otherwise, we must emphasize, the straight relationship between Chemistry and Pharmacy. Actually, since Chemistry replaced Alchemy, Pharmacy and Chemistry have been side by side, coexisting in a fruitful manner, in the multidisciplinary world of science. We can improve more and more this relationship in the benefit of life.

The last century was celebrated as the Pharmacy Century, due to many and important discoveries for mankind in the health area, prolonging the life of the populations in general, and trying to solve the main health problems we have been facing. Taken into account the partnership we mentioned above, Chemistry Century was indirectly commemorated.

Notwithstanding, there is much more to do. So, let us join our partners in this important journey. Together, Pharmacists and Chemists will work towards the improvement of life in the Planet!

Elizabeth Igne Ferreira

Scientific Editor 